\title{
Brain Beta-Catenin Signalling During Stress and Depression
}

\author{
Chuin Hau Teo Tomoko Soga Ishwar S. Parhar \\ Brain Research Institute Monash Sunway (BRIMS), School of Medicine and Health Sciences, Monash \\ University Malaysia, Sunway, Selangor Malaysia
}

\section{Key Words}

Wnt • GSK3 $•$ Glucocorticoids • Serotonin • miRNA

\begin{abstract}
Beta-catenin is a protein with dual functions in the cell, playing a role in both adhesion between cells as well as gene transcription via the canonical Wnt signalling pathway. In the canonical Wnt signalling pathway, beta-catenin again plays multiple roles. In the embryonic stage, the regulation of beta-catenin levels activates genes that govern cell proliferation and differentiation. In an adult organism, beta-catenin continues to regulate the cell cycle - as a result over-expression of beta-catenin may lead to cancer. In the brain, dysfunctions in Wnt signalling related to beta-catenin levels may also cause various pathological conditions like Alzheimer's disease, Parkinson's disease, and depression. Beta-catenin can be influenced by stressful conditions and increases in glucocorticoid levels. In addition, beta-catenin can be regulated by neurotransmitters such as serotonin and dopamine. Fluctuations in betacatenin in brain regions under duress have been associated with depressive-like behaviours. It is theorized that the change in behaviour can be attributed to the regulation of Dicer by betacatenin. Dicer, a protein that produces micro-RNAs in the cell, is a target gene for beta-catenin. Amongst the micro-RNA that it produces are those involved in stress resilience. In this way, beta-catenin has taken its place in the well-studied biochemistry of stress and depression, and future research into this interesting protein may yet yield fruitful results in that field.
\end{abstract}

\section{Introduction}

Stress refers to a state of emotional or mental strain, where elements that induce stress cause a psychological phenomenon that has its causes in biological changes in the body [1]. Such elements are called stressors and may come from various sources such as financial, health, or personal issues.

Stress can be categorized as one of two forms, depending on its source and duration; acute stress and chronic stress. Acute stress is common and short-term in nature; stressful events as different as racing at high speeds or rushing for an oncoming deadline can both be sources of acute stress. Thus, an acute stressor can be defined as an isolated event which 
is perceived as an uncertain or unpredictable situation, and acute stress is the physiological response to such an event [1].

Chronic stress, on the other hand, occurs when stressful situations become a long-term constant; unhappy relationships, poverty, or undesirable careers can all be sources of it. Whereas acute stress may serve as an adaptive response to stressors, chronic stress is more pathologically undesirable, as the constant presence of the stressors prevents physiological recovery from a stressful state. Major depressive disorder is commonly associated with chronic stress [2-6]. It is a diagnosis which has been increasing in recent years, particularly amongst adolescents [7], and the World Health Organization currently estimates more than 300 million sufferers of depression worldwide [8]. Chronic stress is linked with increased onset of major depression from a psychological perspective [2, 5], but from a neurobiological perspective, it has also been shown to alter the hypothalamo-pituitary-adrenal (HPA) system [3]. Chronic stress may also induce a reduction in hippocampus and prefrontal cortex volume - possibly leading to impairment of memory and emotional control - as well as increased dendritic growth in the amygdala, causing increased anxiety and aggression; these too are symptoms of major depression [6].

Under stressful conditions, whether acute or chronic, the biological stress response is triggered, leading to the release of adrenocorticotropin hormone (ACTH) into the blood, which subsequently stimulates synthesis and release of glucocorticoids [9]. Chronic stress has long been associated with major depressive disorder, as findings in the hypothalamicpituitary-adrenal (HPA) axis of animals subjected to chronic stress demonstrate similar symptoms to that found in depressed patients; namely an increase in the central drive of the HPA axis, causing an increased secretion of glucocorticoids, an impaired negative feedback control, and hypertrophy of the adrenal gland [10]. The increased release of glucocorticoids is sustained, and although excess glucocorticoids within the body over a prolonged duration can be damaging, so can hypoactivity of glucocorticoids, which also develops in long-term chronic stress [1].

Amongst the many biological components that undergo changes during stress and depression include glucocorticoids, the serotonergic system, the Wnt signalling pathway, and beta-catenin. This review examines the roles of beta-catenin in the brain and its' physiological functions under pathological conditions, particularly during stress and depression.

\section{Beta-catenin in the central nervous system}

The structure and evolutionary conservation of beta-catenin

First discovered in the $1980 \mathrm{~s}$, beta-catenin is a protein involved in both inter-cellular adhesion and gene transcription $[11,12]$. Beta-catenin consists of 781 amino acids, and its core region has 12 copies of an armadillo repeat, which is a 42 amino acid sequence motif. These repeats form a positive-charged groove which serves as the interaction site for many betacatenin partners [13]. The core region containing the repeats is evolutionarily-conserved, with cnidarian beta-catenin exhibiting close to $80 \%$ homology with the mammalian betacatenin when comparing the repeat domain. In fact, all vertebrate beta-catenins are largely similar and belong in the same clade [14], again indicating the importance of beta-catenin as a highly conserved protein (Fig. 1). The terminus regions of beta-catenin are more susceptible to digestion by proteases; they act as scaffolding for multi-protein complexes. The N-terminal of beta-catenin is the location where the beta-catenin/E-cadherin complex is connected to alpha-catenin, which allows alpha-catenin to bind to F-actin and manipulate the actin cytoskeleton of the cell [15] (Fig. 2).

Brain beta-catenin expression and function

Beta-catenin is ubiquitously present in the mammalian brain. In the brain of rodents, the expression of beta-catenin has been reported in the prefrontal cortex [16], the dorsal 
Fig. 1. Phylogenetic tree of vertebrates and non-vertebrates for beta-catenin encompassing the entire gene sequence of the protein. Phylogenetic tree constructed with information obtained from the Ensembl (www.ensembl.org) analysis of beta-catenin gene (ctnnb1) orthologues comparing homo sapiens with other species.

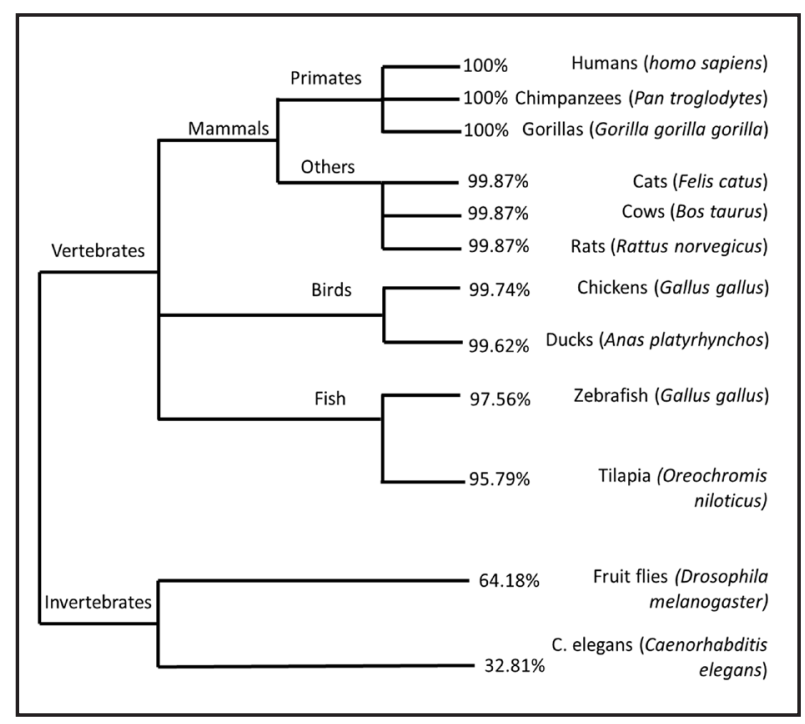

Fig. 2. Beta-catenin protein structure. Phosphorylation of the N-terminal region, a long a-helix sequence, allows B-TrCP to identify, and ubiquinate the protein, targeting it for proteasome degradation. The $\mathrm{C}$-terminal acts as a transactivation domain in interactions with TCF/LEF1 transcription factors, binding to the DNA-binding domain on the transcription factors to activate them.

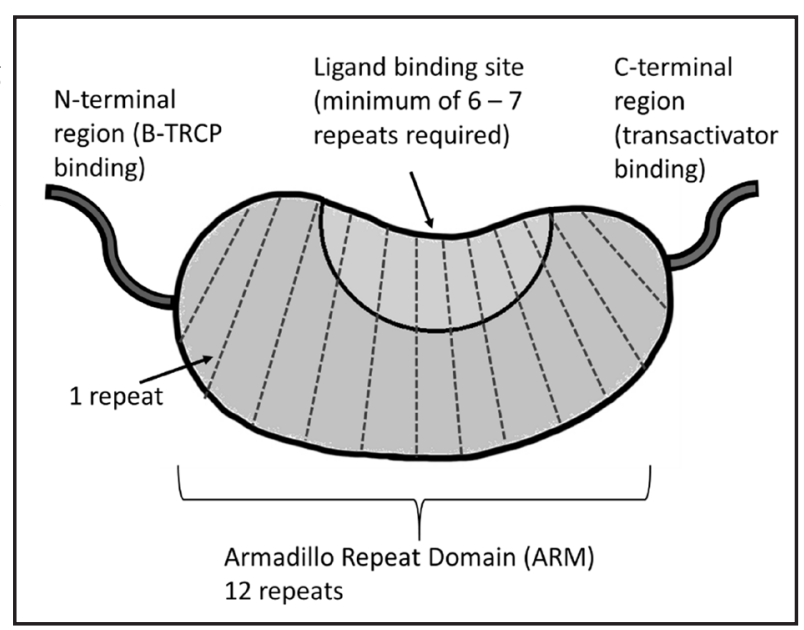

hippocampus [17], the nucleus accumbens [18], the basal amygdala [19, 20] and the hypothalamus [21].

In the brain, beta-catenin expression is at its highest during the developmental stage and cytoplasmic levels peak in neurons at day 5 in mice [22]. Beta-catenin mRNA levels decline in the post-developmental stage, which persists into adulthood. However, with progressive aging, beta-catenin proteins exhibit higher levels [23].

Control of beta-catenin levels during development of the brain is important, as overexpression of the gene may cause increase of neural out-growth and decrease of differentiation, while prematurely inhibiting expression of beta-catenin before its natural decline may cause the progenitor neurons to exit the cell cycle early with increased neuronal differentiation [24].

Beta-catenin has two main roles. Its dual role makes it a versatile protein, one that has been implicated in many diverse functions in a living organism.

It can act as an adhesion protein, where it serves as an anchor for cadherin, which is then linked to the actin cytoskeleton of the cell via alpha-catenin, thus binding the cells together [15]. As an adhesion protein, beta-catenin can affect synaptic stability between hippocampal neurons [25], hypothalamic neurons during the estrous cycle [26] and also neurons within the amygdala, where its activity correlates to the formation and consolidation of memory in the brain [19]. Within these regions, beta-catenin can be regulated by estrogen [27].

Furthermore, beta-catenin has been associated with cellular differentiation and development from an embryological state [28]. It also plays a role in the formation of 
memory via neuroplasticity, a process associated with both of its roles [19, 20]. Dysfunctions related to beta-catenin have been implicated in the causes of pathological conditions such as depression [16, 17, 29], neurodegenerative diseases [30, 31] and cancer [28, 32-34].

Beta-catenin's second role is to serve as an important component of the canonical Wnt signaling pathway $[13,35,36]$, a pathway which warrants a more detailed description below.

\section{The Wnt signalling Pathway}

The Wnt signalling pathway is a highly conserved signal transduction pathway, of which three have been identified thus far: the canonical Wnt pathway, the non-canonical planar cell polarity pathway, and finally the non-canonical Wnt/calcium pathway [37]. Although all three pathways have the same beginning, with a Wnt protein binding to a Frizzled receptor, they subsequently embark upon different signalling pathways and thus regulate different aspects of the cell [37].

Beta-catenin is vital for the canonical Wnt signalling pathway. When the pathway is inactive, beta-catenin is phosphorylated by glycogen synthase kinase $3 \beta$ (GSK3 $\beta$ ) and bound to a destruction complex before being ubiquinated by beta-transducin repeat-containing proteins ( $\beta$-TrCP) [38]. This marks beta-catenin for degradation by proteasomes (Fig. 3).

When Wnt protein binds to the Frizzled transmembrane receptors and its co-receptors Low density lipoprotein-Related Protein 5/6 (LRP5/6), the Wnt pathway becomes active. The destruction complex is bound to the activated Frizzled receptors. The phosphorylated beta-catenin remains in place but is now no longer ubiquinated by $\beta-\operatorname{TrCP}$, taking up space. This results in newly synthesized beta-catenin not being bound to the destruction complex, but instead allowed to increase in levels and saturate the cytoplasm. At that point, betacatenin then translocates into the nucleus where acts as an co-activator and associates with TCF/LEF1, a family of multifunctional transcription factors (Fig. 3).

Transcription of the Wnt pathway target genes then proceeds [39], such as neurogenin1 and NeuroD1 which govern neuronal differentiation [40]. The genes transcribed would be dependent on which of the isoforms of the TCF/LEF1 family that beta-catenin binds to [41].

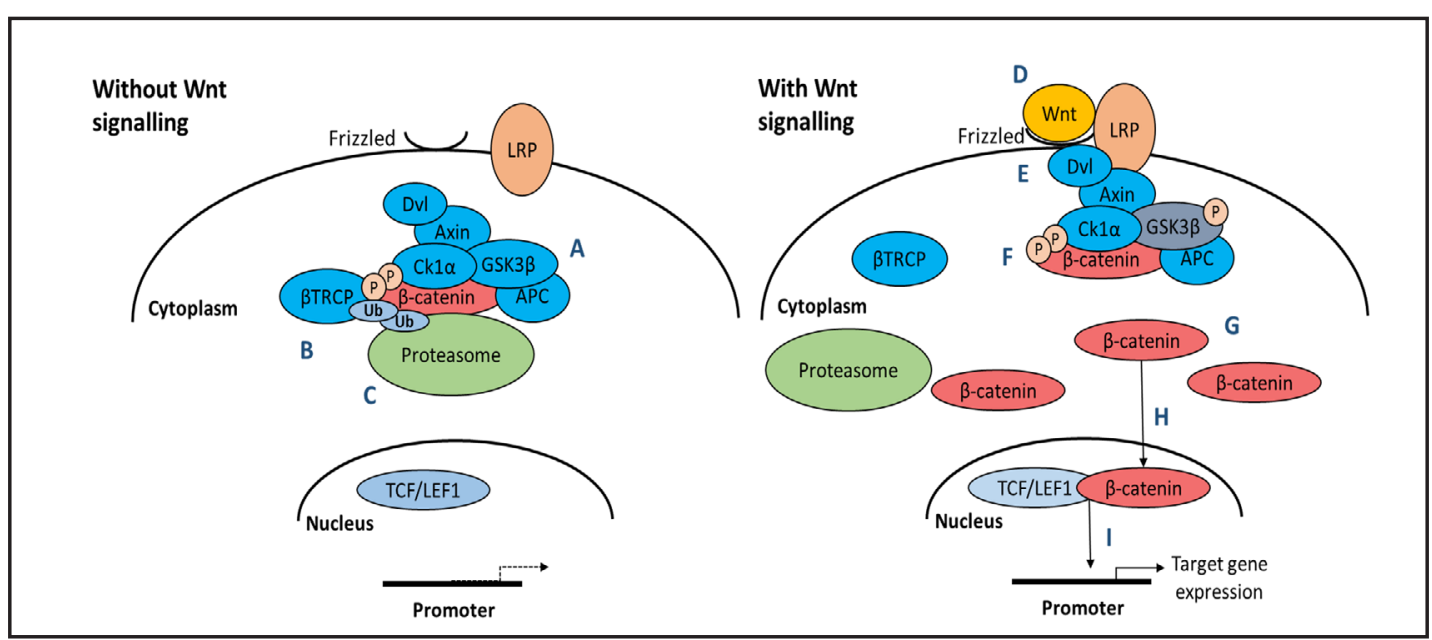

Fig. 3. Wnt signalling pathway. A. Beta-catenin is bound by the destruction complex and phosphorylated by GSK3 $\beta$. B. Beta-catenin is ubiquinated by $\beta$ TRCP. C. Beta-catenin is digested by proteasomes. D. Wnt binds to Frizzled receptor and LRP co-receptors. E. Destruction complex is bound by LRP. F. Beta-catenin is phosphorylated by GSK3 $\beta$, but ubiquitination does not occur. G. Newly synthesized beta-catenin begin to accumulate in the cytoplasm. H. Beta-catenin translocates into the nucleus after saturation. I. Beta-catenin associates with TCF/LEF1 and transcribe target genes. Dishevelled protein (Dvl), Low density lipoproteinRelated Protein (LRP) Adenoma Polyposis Coli (APC), glycogen synthase kinase $3 \beta$ (GSK3 $\beta$ ), casein kinase $1(\mathrm{Ck} 1 \alpha)$, Transcription factor/Lymphoid-enhancing binding factor 1 (TCF/LEF1), beta-transducin repeatcontaining proteins $(\beta-\mathrm{TRCP})$. 
Teo/Soga/Parhar: Brain Beta-Catenin During Stress

Factors regulating beta-catenin

Within the Wnt signalling pathway, beta-catenin is governed by various regulatory mechanisms. These mechanisms tend to act on the destruction complex: in general terms, beta-catenin levels are controlled indirectly by regulating the rate of destruction (Fig. 3). As these influences act upon the destruction complex rather than directly altering Wnt binding rates, they induce constitutive changes independent of upstream signalling of Wnt.

GSK3 $\beta$ in its active, unphosphorylated form [42], is required for phosphorylation of beta-catenin to lead to its degradation, and thus its presence - or lack thereof - influences the levels of beta-catenin [43]. Thus, any changes in cellular biochemistry that modifies the levels of ser9-phosphorylated-GSK3 $\beta$ may in turn alter beta-catenin levels. The role of GSK3 $\beta$ and other protein kinases in the modulation of beta-catenin has been well-summarized in recent reviews $[43,44]$.

\section{Beta-catenin, stress and depression:}

\section{Beta-catenin and stress}

From a biological point of view, stress can result in changes in the endocrine system, and can cause an increase or decrease in the expression of various genes associated with the stress response [45]. As detailed in the introduction, the form of stress most commonly associated with depression is chronic stress.

After being exposed to chronic stress via foot shocks, beta-catenin levels in the stressed mice were found to be decreased within the basolateral amygdala, but increased in the dorsal hippocampus [46]. This was associated with increased anxiety and fear-like behaviour in those mice and suggests that basal changes in beta-catenin levels due to chronic stress affects stress-related behaviour [46]. In contrast, beta-catenin in the nucleus accumbens appears to facilitate resilient responses to acute stressors [47]. As the presence of acute stress in individuals already suffering from high chronic stress is a strong indicator for major depressive episodes, the study's correlation of increased levels of beta-catenin in the nucleus accumbens with higher suppression of stress behaviour appears to suggest betacatenin may exert a protective effect in depression, at least in the nucleus accumbens. On the other hand, downregulation of beta-catenin expression with sulindac enhanced stress-like behaviour while upregulation of the Wnt pathway with the use of lithium reduced it [47].

Chronic stress is a form of stress that can be mediated by beta-catenin through one of its target genes, Dicer-1 [18]. The product of Dicer-1 acts to cleave precursor RNA molecules to produce microRNAs (miRNA), and an elevation of miRNA levels has been associated with stress adaptations [48-50]. Mice with an excised beta-catenin gene in the nucleus accumbens are more susceptible to social defeat-induced chronic stress as the down-stream target of beta-catenin, Dicer-1, can no longer be upregulated to produce miRNAs important in resisting the effects of stress [18].

Chronic stress induced by dexamethasone decreased phosphorylation of ser 9 on GSK3 $\beta$ - this resulted in an increase in GSK3 $\beta$ activity and a corresponding decrease in beta-catenin levels [51].

During times of stress, glucocorticoid levels are increased, which in turn affect various other biological components in our body. Particularly in the brain, elevated glucocorticoid levels may directly affect neuronal functionality [52]. Chronic stress reduces beta-catenin and phosphorylated GSK3 $\beta$ levels within the pre-frontal cortex and dorsal hippocampus after 14 days of daily forced swim tests, which causes elevated total GSK3 $\beta$ levels, reduced phosphorylated GSK3 $\beta$ expression, and reduced beta-catenin levels $[16,38]$. Elevated total GSK3 $\beta$ levels combined with reduced phosphorylated GSK3 $\beta$ expression indicates increased overall levels of dephosphorylated, active GSK3 $\beta$. Under those situations, beta-catenin would be digested by the destruction complex, resulting in the reduced levels. Furthermore, the increase in glucocorticoid levels induced by stress has also been shown to result in degeneration of the hippocampal neurons. Mice exposed to stress show elevated levels of 
Dickkopf-1 (Dkk-1), which blocks the Wnt signalling pathway resulting in hippocampal damage. Dkk-1 acts to promote endocytosis of LRP5/6, which prevents the Wnt signalling pathway from activating, thus causing dendritic atrophy and neuronal loss [53].

Stress can also have a physiological effect in the form of oxidative stress. Inducing oxidative stress in the hypothalamus and amgydala has been correlated with an increase in anxiety-like behaviour [54,55]. Oxidative stress involves an increase in the generation of reactive oxygen species (ROS), which can damage various components of the cell such as its DNA, protein or lipids - in order to cope with this stress, cells adapt their constitution via several pathways including the Wnt beta-catenin pathway [56, 57]. During oxidative stress, beta-catenin deficient mice are unable to suppress the generation of ROS [58]. Subsequently, over-expression of beta-catenin binds to FoxO, an important molecule for oxidative stress tolerance and cellular proliferation [59]; this inhibits cell cycle progression [60].

\section{Beta-catenin and depression}

Depression is a neurological disorder that may be related to beta-catenin dysfunction within the brain. The link between depression and Wnt signalling, of which beta-catenin is an important component, began with the discovery that GSK3 $\beta$ was effectively inhibited by lithium, which was used as a treatment for bipolar affective disorders, and at the same time, also found to increase beta-catenin saturation in in vitro cell cultures [61]. This effect was also observed in the rat brain [62] and later, beta-catenin and GSK3 $\beta$ expression was implicated in depressive-like behaviour in the frontal cortex and hippocampus [29, 63 , 64]. Over-expression of beta-catenin causes similar behavioural effects as that of inhibition of GSK3 $\beta$ via phosphorylation, which has previously been identified as a means of rescuing depressive-like behaviour. [29, 64]. Dysfunctions in Wnt signalling - namely, the downregulation of Dishevelled, a protein that is part of the destruction complex, as well as an increase in levels and activity of dephosphorylated GSK3 $\beta$ - can be seen in the nucleus accumbens of mice in association with increased susceptibility to social defeat stress and depression-like behaviour. [65].

Within the human brain, alterations in beta-catenin levels have been demonstrated during cases of depression. Brain samples of patients suffering from major depressive disorder are found to exhibit a dysregulation of Wnt signalling activity. These samples show lowered beta-catenin protein levels in the nucleus accumbens even though betacatenin mRNA levels remain unchanged. This indicates that depression does not involve the down-regulation of beta-catenin expression at a genetic level, but instead could be linked specifically to alterations in the functionality of the beta-catenin peptide within the nucleus, causing a reduction in viable, detectable beta-catenin protein [18]. Furthermore, an increase in dephosphorylated GSK3 $\beta$ is associated with lowered beta-catenin protein levels in the prefrontal cortex [66].

The link between Wnt signalling and anti-depressants was first conceived when it was discovered that hippocampal neurogenesis was mandatory for behavioural effects of anti-depressants to manifest. Disruption of the neurogenesis in the hippocampus induced by anti-depressant treatment was shown to prevent neurogenic and behavioural effects of fluoxetine and imipramine, indicating the importance of the growth of new hippocampal neurons in anti-depressant action [67]. As beta-catenin and the Wnt pathway are both a vital step in cell proliferation, research into the links between beta-catenin and anti-depressants then began to step up.

Chronic stress-induced reductions in beta-catenin and phosphorylated GSK3 $\beta$ within the pre-frontal cortex could be alleviated with the administration of the antidepressant citalopram, which recovered both behavioural changes as well as beta-catenin and phosphorylated GSK3 $\beta$ levels [16]. The static levels of overall GSK3 $\beta$ means that a decrease in phosphorylated, inactivated GSK3 $\beta$ would correspond to an increase in dephosphorylated, activated GSK3 $\beta$; this then reduces relative beta-catenin levels due to the role of dephosphorylated GSK3 $\beta$ in the destruction complex. Similarly, in the dorsal 
hippocampus, citalopram can rescue depression of overall beta-catenin levels brought about by chronic stress. Citalopram-treated chronically stressed rats exhibit normal GSK3 $\beta$ and beta-catenin levels in comparison to the reduced levels observed in untreated, stressed rats [17]. However, administration of the Dvl inhibitor sulindac negates the restorative effects of citalopram, suggesting that Dvl may have a part to play in citalopram's effect on betacatenin [17]. Although the interaction of Dvl with citalopram has yet to be clarified, since sulindac acts to suppress Wnt/beta-catenin signalling by binding to the PDZ domain of Dvl which functions in relaying signals from membrane-bound Wnt receptors downstream - it is possible that citalopram acts on that same domain to promote accumulation of beta-catenin.

The use of the dual reuptake inhibitor (SNRI) venlafaxine also demonstrated an increase in the activity of hippocampal beta-catenin, supporting the idea that beta-catenin may play a role in the proliferation of hippocampal neurons observed in anti-depressant use. Administration of the SNRI increases nuclear beta-catenin levels; the rise in beta-catenin levels within the nucleus may upregulate the expression of cell cycle regulator genes which then enhances neuronal proliferation. However, the exact mechanism by which venlafaxine acts to induce the Wnt signalling pathway is yet unclear [68]. The anti-depressant resveratrol was also shown to downregulate hyperactivity of the HPA axis and upregulate the activity of beta-catenin in the hippocampus of rats suffering from subclinical hypothyroidism [69].

Although the mechanisms between the reduction of beta-catenin and the onset of anxiety and depressive-related symptoms have not been clearly elucidated in most studies, it has been suggested that a key role may lie with Dicer1, one of the target genes for beta-catenin [18]. Dicer 1 codes for the Dicer protein, which is involved in the cleaving and formation of all micro-RNA (miRNA) end-products. MiRNAs such as miR-124, miR-135, and miR-15a have been shown in separate studies to play a role in stress adaptations [48-50]. In addition to that, a general decrease in miRNA expression throughout the brain has been found to be consistent with lowered activation of the frontal cortex in depressed human subjects [70], while up-regulation of the miR-16 miRNA in the raphe nuclei and hippocampus was found to induce depressive behaviour [71]. More recently, in the medial prefrontal cortex, up-regulation of miRNAs that suppress mRNAs for proteins involved with neural processes such as GABAergic and dopaminergic synaptic activity, as well as synaptic vesicle recycling, was observed in rats that had depression induced via chronic unpredictable mild stress [72]. These studies appear to indicate that upregulation and downregulation of miRNAs

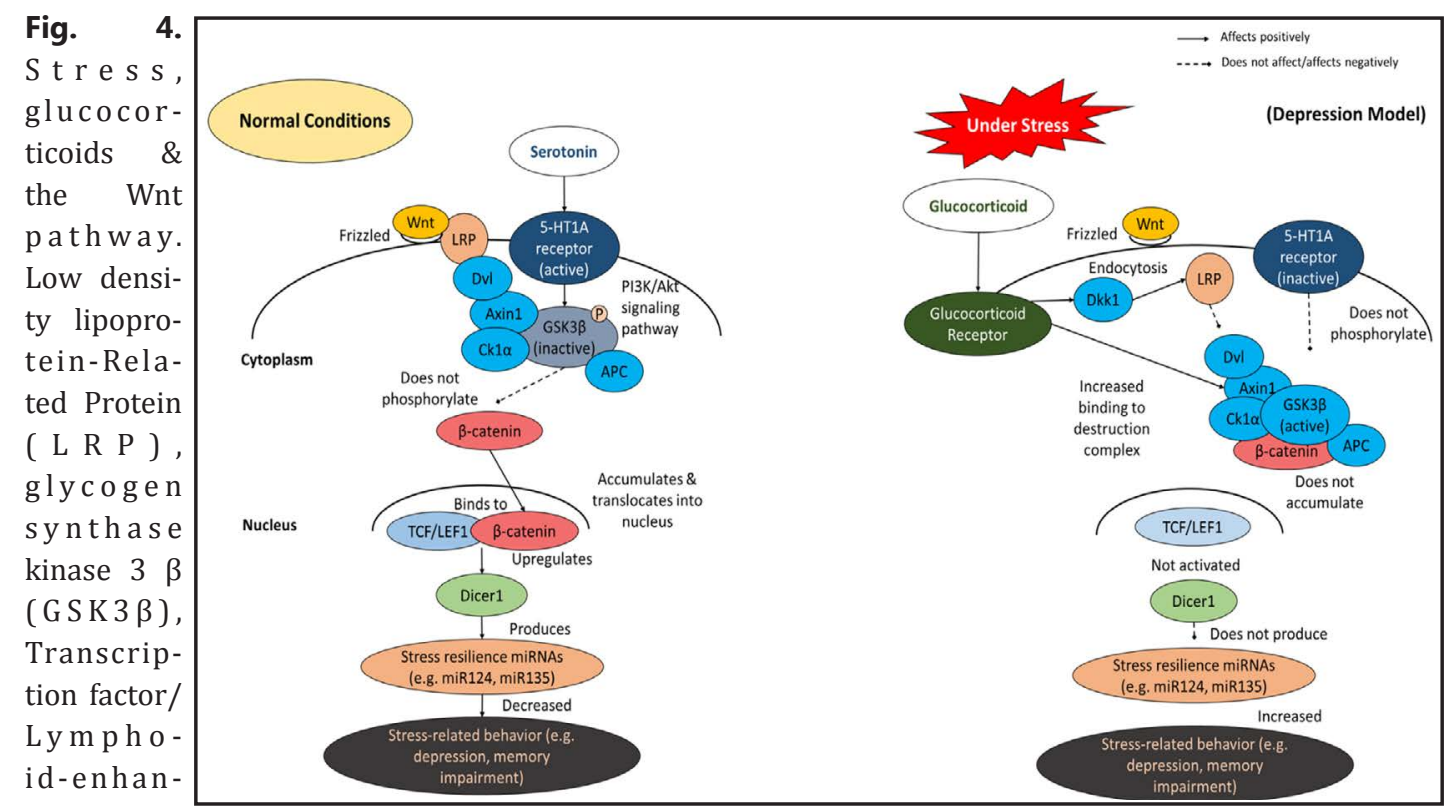

cing binding factor 1 (TCF/LEF1), Dickkopf-related protein 1 (Dkk1). 
Teo/Soga/Parhar: Brain Beta-Catenin During Stress

may vary from region to region in the brain during depressive-like conditions, and that these fluctuations are involved in changes related to neural processes. As Dicer is again a key protein involved in the formation of miRNAs, it is very likely that Wnt signalling and beta-catenin, which control Dicer1 gene expression, have an important part to play in this pathway (Fig. 4).

\section{Serotonergic regulation of beta-catenin}

Serotonergic-based antidepressants such as citalopram and fluoxetine can alter betacatenin levels. Although not within the brain, during hepatocellular cancer, serotonin (5-HT) has been directly implicated in cell proliferation via its activation of the 5-HT7 and 5-HT1D receptors. It was suggested that activation of these receptors interferes with the beta-catenin destruction complex and attenuates cytoplasmic and nuclear beta-catenin levels [73]. The presence of this mechanism strongly suggests that 5-HT and beta-catenin in the brain may interact via serotonin receptors.

This has been borne out in numerous previous studies involving the interactions of 5-HT with GSK3 $\beta$ and beta-catenin in various parts of the brain. For example, in vivo treatment with agonists and antagonists for both 5-HT1A and 5-HT2 receptors brought about changes in GSK3 $\beta$ phosphorylation levels within the prefrontal cortex, hippocampus and striatum of the brain - activation of 5-HT1A receptors increased phosphorylated GSK3 $\beta$, while activated 5-HT2 receptors decreased it [74]. As the levels of phosphorylated GSK3 $\beta$ are inversely correlated with beta-catenin activity and availability [43], Li's study suggested that activating 5-HT1A receptors decreases beta-catenin activity, and vice versa for 5-HT2.

In the hippocampus, the selective serotonin reuptake inhibitor (SSRI) fluoxetine has also been demonstrated to regulate neurogenesis via up-regulating phosphorylation of GSK3 $\beta$, thereby inactivating it; this effect was shown to be dependent on 5-HT1A receptors [75]. The up-regulation of phosphorylated GSK3 $\beta$ was accompanied by an increase in nuclear localization of beta-catenin, indicating increased Wnt signalling, and subsequently increased cell proliferation [75].

The 5-HT7 receptor is also coupled to the G12-protein, which in turn has demonstrated the ability to cause beta-catenin to dissociate from cadherins when activated - this naturally increases the amount of free, unphosphorylated beta-catenin in the cytoplasm [76, 77]. It may be of note that 5-HT7 receptors have shown to display cross-reactivity with agonists for 5-HT1A, and both are highly expressed in regions of the brain related to depression during major depressive disorders [78].

\section{Conclusion and Outlook}

Depression and stress are inextricably intertwined, as each feeds on the other. Taken together, these results paint a picture where beta-catenin, via the Wnt signalling pathway, plays an important role in stress response and depression. First, the stress response impacts beta-catenin expression. Stress increases glucocorticoid levels, which may then be responsible for the lowering of beta-catenin levels that have been observed in the various studies discussed in this review. This in turn influences cellular function. The reduction in beta-catenin levels further degrade the organism's ability to resist stress through miRNA upregulation.

Although the exact role of miRNA in depression is yet unclear, it is suggested that micro-RNAs may act on untranslated regions of genes such as 5-HT1A and the serotonin transporter (SERT) gene that have an important function in the serotonergic system [50]. Bioinformatics analysis show that that miR-135 suppress the transcripts of both 5-HT1A and SERT - that reduces the ability of synapses to recycle serotonin [50]. If the ability of an organism to resist stress deteriorates unchecked, this may potentially cause a feedback loop cascade culminating in depression. 
While constant overexpression of beta-catenin is characteristic in cancer [79], changes in beta-catenin levels under depression is dependent upon the region of the brain $[16,17,29$, $46,69]$ and not as easily definable as its role in cancer; as such, beta-catenin in depression requires a more varied approach to its investigation. Furthermore, beta-catenin in cancer is closely linked to the mutation of p53 [80, 81], whereas in depression, alterations in betacatenin levels appears to be more associated with changes in the phosphorylation state of GSK3 $\beta$ and the serotonergic system [16, 17, 62-64].

At the moment, therapeutic targeting of beta-catenin is in its early stages of development $[82,83]$. Due to the importance of Wnt signalling throughout the body - in which betacatenin plays a crucial role - any treatment targeting beta-catenin may well be accompanied by adverse side-effects. Furthermore, as has been detailed in this review, even in the brain alone, the increase or decrease in beta-catenin levels during depression and stress are regiondependent. There is already a beta-catenin specific antagonist (PRI-724) undergoing clinical trials $[83,84]$; although this agent shows promise, its trials focus primarily on intestinal and pancreatic cancer. In terms of depression, the question of delivering beta-catenin treatment to specific regions of the brain is yet to be addressed. Of course, there are other potential agents under research, such as MSAB [85] and ICG-001, inhibitors small enough to potentially pass through the blood brain barrier [86]. Should the problem of site specific drug delivery in the brain be resolved, control over beta-catenin levels has potential to be a powerful tool in combating depression, as well as a host of other Wnt pathway-related disorders. Furthermore, as discussed in this review, the ubiquitous presence of beta-catenin within the brain as well as its changed expression levels during depression confers great potential as a diagnostic marker in the biology of major depressive disorder.

In conclusion, changes in beta-catenin have a key role in the pathology of depression. It may be interesting to consider beta-catenin as a potential diagnostic marker for depression, as well as a novel pharmacological target in the treatment of major depressive disorder. Further research in this complex yet fascinating area may yet discover new avenues of combating depression.

\section{Disclosure Statement}

The authors have nothing to disclose.

\section{References}

1 Moisan M-P, Le Moal M: Le stress dans tous ses états. Med Sci (Paris) 2012;28:612-617.

2 Khan S, Khan RA: Chronic Stress Leads to Anxiety and Depression. Ann Psychiatry Ment Health 2017;5:

-3 Tafet GE, Bernardini R: Psychoneuroendocrinological links between chronic stress and depression. Prog Neuropsychopharmacol Biol Psychiatry 2003;27:893-903.

4 Robles TF, Glaser R, Kiecolt-Glaser JK: Out of Balance:A New Look at Chronic Stress, Depression, and Immunity. Curr Dir Psychol Sci 2005;14:111-115.

5 Hammen C, Kim EY, Eberhart NK, Brennan PA: Chronic and acute stress and the prediction of major depression in women. Depress Anxiety 2009;26:718-723.

6 McEwen BS: Glucocorticoids, depression, and mood disorders: structural remodeling in the brain. Metabolism 2005;54:20-23.

7 Mojtabai R, Olfson M, Han B: National Trends in the Prevalence and Treatment of Depression in Adolescents and Young Adults. Pediatrics 2016;10.1542/peds.2016-1878.

8 W.H.O: Depression - Fact Sheet. 2017;

- Henry JP: Biological basis of the stress response. Integr Physiol Behav Sci 1992;27:66-83.

10 Checkley S: The neuroendocrinology of depression and chronic stress. Br Med Bull 1996;52:597-617.

$\checkmark 11$ Ozawa M, Baribault H, Kemler R: The cytoplasmic domain of the cell adhesion molecule uvomorulin associates with three independent proteins structurally related in different species. EMBO J 1989;8:17111717.

$\checkmark 12$ Wiechaus E, Riggleman R: Autonomous requirements for the segment polarity gene armadillo during Drosophila embryogenesis. Cell 1987;49:177-184. 


\section{SIGiNAIS}

Neurosignals 2018;26:31-42

\begin{tabular}{l|l}
\hline DOI: $10.1159 / 000487764$ & (C) 2018 The Author(s). Published by S. Karger AG, Basel
\end{tabular}

Published online: February 27, 2018

www.karger.com/nsg

Teo/Soga/Parhar: Brain Beta-Catenin During Stress

13 Huber O, Korn R, McLaughlin J, Ohsugi M, Hermann BG, Kemler R: Nuclear localization of $\beta$-catenin by interaction with transcription factor LEF-1. Mech Dev 1996;59:3-10.

14 Zhao Z, Reynolds AM, Gaucher EA: The evolutionary history of the catenin gene family during metazoan evolution. BMC Evol Biol 2011;11:11:198.

15 Drees F, Pokutta S, Yamada S, Nelson WJ, Weis WI: $\alpha$-Catenin Is a Molecular Switch that Binds E-Cadherin$\beta$-Catenin and Regulates Actin-Filament Assembly. Cell 2005;123:903-915.

16 Chen YC, Tan QR, Dang W, Wang HN, Zhang RB, Li ZY, Lin H, Liu R: The effect of citalopram on chronic stress-induced depressive-like behavior in rats through GSK3 $\beta / \beta$-catenin activation in the medial prefrontal cortex. Brain Res Bull 2012;88:338-344.

17 Liu R, Dang W, Miao JT, Su CJ, Wang HN, Chen YC, Tan QR: Citalopram alleviates chronic stress induced depression-like behaviors in rats by activating GSK3 $\beta$ signaling in dorsal hippocampus. Brain Res 2012;1467:10-17.

18 Dias C, Feng J, Sun H, Shao NY, Mazei-Robison MS, Damez-Werno D, Scobie K, Bagot R, LaBonte B, Ribeiro E, Liu X, KEnnedy P, Vialou V, Ferguson D, Pena C, Calipari ES, Koo JW, Mouzon E, Ghose S, Tamminga C, Neve RL, Shen L, Nestler EJ: $\beta$-catenin mediates stress resilience through Dicer1/microRNA regulation. Nature 2014;516:51-55.

19 Maguschak AK, Ressler KJ: b-catenin is required for memory consolidation. Nat Neurosci 2008;11:13191326.

-20 Maguschak AK, Ressler KJ: Wnt signalling in amygdala-dependent learning and memory. J Neurosci 2011;31:13057-13067.

-21 Lee JM, Kim KC, Yu SW, Kim EK: Wnt3a upregulates brain-derived insulin by increasing NeuroD1 via Wnt/ $\beta$-catenin signaling in the hypothalamus. Mol Brain 2016;9:24.

22 Coyle-Rink J, Del Valle L, Sweet T, Khalili K, Amini S: Developmental Expression of Wnt Signaling Factors in Mouse Brain. Cancer Biol Ther 2002;1:640-645.

-23 Lu T, Aron L, Zullo J, Pan Y, Kim H, Chen Y, Yang TH, Kim HM, Drake D, Liu XS, Bennett DA, Colaiacovo MP, Yankner BA: REST and stress resistance in ageing and Alzheimer's disease. Nature 2014;507:448-454.

24 Chenn A, Walsh CA: Regulation of cerebral cortical size by control of cell cycle exit in neural precursors. Science 2002;297:365-369.

25 Mills F, Bartlett TE, Dissing-Olesen L, Wisniewska MB, Kuznicki J, Macvicar BA, Wang YT, Bamji SX: Cognitive flexibility and long-term depression (LTD) are impaired following $\beta$-catenin stabilization in vivo. PNAS 2014;111:8631-8636.

-26 Barrera-Ocampo A, Gutierrez-Vargas J, Garcia-Segura LM, Cardona Gomez GP: Glycogen Synthase Kinase3b/b-Catenin Signaling in the Rat Hypothalamus During the Estrous Cycle. J Neurosci Res 2012;90:10781084.

27 Cardona-Gomez P, Perez M, Avila J, Garcia-Segura LM, Wandosell F: Estradiol inhibits GSK3 and regulates interaction of estrogen receptors, GSK3, and beta-catenin in the hippocampus. Mol Cell Neurosci 2004;25:363-373.

28 Waltzer L, Bienz M: The control of beta-catenin and TCF during embryonic development and cancer. Cancer Metastasis Rev 1999;18:231-246.

29 Gould TD, Einat H, O'Donnell KC, Picchini AM, Schloesser RJ, Manji HK: Beta-catenin overexpression in the mouse brain phenocopies lithium-sensitive behaviors. Neuropsychopharmacology 2007;32:2173-2183.

30 Berwick DC, Harvey K: The importance of Wnt signalling for neurodegeneration in Parkinson's disease. Biochem Soc Trans 2012;40:1123-1128.

-31 De Ferrari GV, Avila ME, MEdina MA, Perez-Palma E, Bustos BI, Alarcon MA: Wnt/ $\beta$-catenin signaling in Alzheimer's disease. CNS Neurol Disord Drug Targets 2014;13:745-754.

-32 Geyer FC, Lacroix-triki M, Kay S, Arnedos M, Lambros MB: Beta-Catenin pathway activation in breast cancer is associated with triple-negative phenotype but not with CTNNB1 mutation. Mod Pathol 2011;24:209-231.

33 MacDonald BT, Tamai K, He X: Wnt/ $\beta$-catenin signaling: components, mechanisms, and diseases. Dev Cell 2009;17:09-26.

-34 Zhan T, Rindtorff N, Boutrous M: Wnt signaling in cancer. Oncogene 2017;36:1461-1473.

-35 Behrens J, von Kries JP, Kuhl M, Bruhn L, Wedlich D, Grosschedl R, Birchmeier W: Functional interaction of $\beta$-catenin with the transcription factor LEF-1. Nature 1996;382:638-642.

-36 Takeichi M: Cadherins: a molecular family important in selective cell-cell adhesion. Annu Rev Biochem 1989;1990:237-252.

-37 Komiya Y, Habas R: Wnt signal transduction pathways. Organogenesis 2008;4:68-75. 
Neurosignals 2018;26:31-42

\begin{tabular}{l|l}
\hline DOI: 10.1159/000487764 & $\begin{array}{l}\text { c } 2018 \text { The Author(s). Published by S. Karger AG, Basel } \\
\text { www.karger.com/nsg }\end{array}$ \\
\hline
\end{tabular}

Teo/Soga/Parhar: Brain Beta-Catenin During Stress

-38 Liu C, Kato Y, Zhang Z, Do VM, Yankner BA, He X: $\beta$-Trcp couples $\beta$-catenin phosphorylation-degradation and regulates Xenopus axis formation. PNAS 1999;96:6273-6278.

-39 Huelsken J, Behrens J: The Wnt signalling pathway. J Cell Sci 2002;115:3977-3978.

40 Hirabayashi Y, YItoh Y, Tabata H, Nakajima K, Akiyama T, Masuyama N, Gotoh Y: The Wnt/ $\beta$-catenin pathway directs neuronal differentiation of cortical neural precursor cells. Development 2004;131:27912801.

41 Cadigan KM, Waterman ML: TCF/LEFs and Wnt Signaling in the Nucleus. Cold Spring Harb Perspect Biol. 2012;4:

-42 Fang X, Yu SX, Lu Y, Bast Jr. RC, Woodgett JR, Mills GB: Phosphorylation and inactivation of glycogen synthase kinase 3 by protein kinase A. PNAS 2000;97:11960-11965.

43 Wu D, Pan W: GSK3: a multifaceted kinase in Wnt signaling. Trends Biochem Sci. 2010;35:161-168.

44 Verheyen EM, Gottardi CJ: Regulation of Wnt/ $\beta$-Catenin Signaling byProtein Kinases. Dev Dyn 2010;239:33-44.

45 Tsigos C, Kyrou I, Kassi E, Chrousos GP: Stress, Endocrine Physiology and Pathophysiology. Endotext [Internet] 2016;

46 Dahlhoff M, Siegmund A, Golub Y, Wolf E, Holsboer F, Wotjak CT: AKT/GSK-3 $\beta / \beta$-catenin signalling within hippocampus and amygdala reflects genetically determined differences in posttraumatic stress disorder like symptoms. Neuroscience 2010;169:1216-1226.

-47 Korem N, Lange R, Hillard CJ, Akirav I: Role of beta-catenin and endocannabinoids in the nucleus accumbens in extinction in rats exposed to shock and reminders. Neuroscience 2017;357:285-294.

48 Higuchi F, Uchida S, Yamagata H, Abe-Higuchi N, Hobara T, Hara K, Kobayashi A, Shintaku T, Itoh Y, Suzuki T, Watanabe Y: Hippocampal MicroRNA-124 Enhances Chronic Stress Resilience in Mice. J Neurosci 2016;36:7253-7267.

49 Volk N, Pape JC, Engel M, Zannas AS, Cattane N, Cattaneo A, Binder EB, Chen A: Amygdalar MicroRNA-15a Is Essential for Coping with Chronic Stress. Cell Rep 2016;17:1882-1891.

-50 Issler O, Haramati S, Paul ED, Maeno H, Navon I, Zwang R, Gil S, Mayberg HS, Dunlop BW, Menke A: MicroRNA 135 Is Essential for Chronic Stress Resiliency, Antidepressant Efficacy, and Intact Serotonergic Activity. Neuron 2014;83:344-360.

51 Garza JC, Guo M, Zhang W, Lu X-Y: Leptin restores adult hippocampal neurogenesis suppressed by chronic unpredictable stress and reverses glucocorticoid-induced inhibition of GSK3 $\beta / \beta$-catenin signaling. Mol Psychiatry 2012;17:790-808.

52 Vyas S, Rodrigues AJ, \#xe3, Silva JM, Tronche F, Almeida OFX, Sousa N, Sotiropoulos I: Chronic Stress and Glucocorticoids: From Neuronal Plasticity to Neurodegeneration. Neural Plast 2016;2016:15.

53 Matrisciano F, Busceti CL, Bucci D, Orlando R, Caruso A, Molinaro G, Cappuccio I, Riozzi B, Gradini R, Motolese M, Caraci F, Copani A, Scaccianoce S, Melchiorri D, Bruno V, Battaglia G, Nicoletti F: Induction of the Wnt Antagonist Dickkopf-1 Is Involved in Stress-Induced Hippocampal Damage. PLoS One 2011;6:e16447.

-54 Bouayed J, Rammal H, Soulimani R: Oxidative stress and anxiety. Oxid Med Cell Longev 2009;2:63-67.

55 Hassan W, Silva CEB, Mohammadzai IU, da Rocha JBT, Landeira-Fernandez J: Association of Oxidative Stress to the Genesis of Anxiety: Implications for Possible Therapeutic Interventions. Curr Neuropharmacol 2014;12:120-139.

56 Martindale JL, Holbrook NJ: Cellular Response to Oxidative Stress: Signaling for Suicide and Survival. J Cell Physiol 2002;192:1-15.

57 Fulda S, Gorman AM, Hori O, Samali A: Cellular Stress Responses: Cell Survival and Cell Death. Int J Cell Biol 2010;2010:1-23.

-58 Lento W, Ito T, Zhao C, Harris JR, Huang W, Jiang C, Owzar K, Piryani S, Racioppi L, Chao N, Reya T: Loss of $\beta$-catenin triggers oxidative stress and impairs hematopoietic regeneration. Genes Dev 2014;28:995-1004.

59 van der Horst A, Burgering BMT: Stressing the role of FoxO proteins in lifespan and disease. Nat Rev Mol Cell Biol 2007;8:440-450.

60 Essers MAG, de Vries-Smits LMM, Barker N, Polderman PE, Boudewijn MTB, Korswagen HC: Functional interaction between [beta]-catenin and FOXO in oxidative stress signaling. Science 2005;308:1181.

61 Chen G, Huang LD, Jiang YM, Manji HK: The mood-stabilizing agent valproate inhibits the activity of glycogen synthase kinase-3. J Neurochem 1999;72:1327-1330.

62 Gould TD, Chen G, Manji HK: In vivo evidence in the brain for lithium inhibition of glycogen synthase kinase-3. Neuropsychopharmacology 2004;29:32-38.

63 Kaidanovich-Beilin O, Milman A, Weizman A, Pick CG, Eldar-Finkleman H: Rapid antidepressive-like activity 


\section{SiGNAis}

\begin{tabular}{l}
\hline Neurosignals 2018;26:31-42 \\
\begin{tabular}{l|l}
\hline DOI: $10.1159 / 000487764$ & $\begin{array}{l}\text { c } 2018 \text { The Author(s). Published by S. Karger AG, Basel } \\
\text { www.karger.com/nsg }\end{array}$ \\
Published online: February 27, 2018
\end{tabular}
\end{tabular}

Teo/Soga/Parhar: Brain Beta-Catenin During Stress

of specific glycogen synthase kinase- 3 inhibitor and its effect on $\beta$-catenin in mouse hippocampus. Biol Psychiatry 2004;55:781-784.

64 Rowe MK, Wiest C, Chuang DM: GSK-3 is a viable potential target for therapeutic intervention in bipolar disorder. Neurosci Biobehav Rev 2007;31:920-931.

65 Wilkinson MB, Dias C, Magida J, Mazei-Robinson M, Lobo MK, Kennedy P, Dietz D, Covington III H, Russo S, Neve R, Ghose S, Tamminga C, Nestler EJ: A Novel Role of the WNT-Dishevelled-GSK3 Signaling Cascade in the Mouse Nucleus Accumbens in a Social Defeat Model of Depression. The J Neurosci 2011;31:9084-9092.

66 Karege F, Perroud N, Burkhardt S, Fernandez R, Ballmann E, La Harpe R, Malafosse A: Protein levels of $\beta$-catenin and activation state of glycogen synthase kinase- $3 \beta$ in major depression. A study with postmortem prefrontal cortex. J Affect Disord 2012;136:185-188.

67 Santarelli L, Saxe M, Gross C, Surget A, Battaglia F, Dulawa S, Weisstaub N, Lee J, Duman R, Arancio O, Belzung C, Hen R: Requirement of hippocampal neurogenesis for the behavioral effects of antidepressants. Science 2003;301:805-809.

68 Mostany R, Valdizan EM, Pazos A: A role for nuclear $\beta$-catenin in SNRI antidepressant-induced hippocampal cell proliferation. Neuropharmacology 2008;55:18-26.

69 Ge JF, Xu YY, Qin G, Cheng JQ Chen FH: Resveratrol ameliorates the anxiety- and depression-like behavior of subclinical hypothyroidism rat: possible involvement of the HPT axis, HPA axis, and Wnt/ $\beta$-catenin Pathway. Front Endocrinol (Lausanne) 2016;7:1-11.

70 Smalheiser NR, Lugli G, Rizavi HS, Torvik VI, Turecki G, Dwivedi Y: MicroRNA expression is down-regulated and reorganized in prefrontal cortex of depressed suicide subjects. PLoS One. 2012;7:e33201.

71 Bai M, Zhu X, Zhang Y, Zhang S, Zhang L, Xue L, Yi J, Yao S, Zhang X: Abnormal hippocampal BDNF and miR16 expression is associated with depression-like behaviors induced by stress during early life. PLoS One 2012;7:e46921.

72 Ma K, Guo L, Xu A, Cui S, Wang JH: Molecular Mechanism for Stress-Induced Depression Assessed by Sequencing miRNA and mRNA in Medial Prefrontal Cortex. PLoS One 2016;11:e0159093-

-73 Fatima S, Shi X, Lin Z, Chen GQ, Pan XH, Wu JCY, Ho JW, Lee NP, Gao H, Zhang G, Lu A, Bian ZX: 5-Hydroxytryptamine promotes hepatocellular carcinoma proliferation by influencing b-catenin. Mol Oncol 2016;10:195-212.

74 Li X, Zhu W, Roh MS, Friedman AB, Rosborough K, Jope RS: In Vivo Regulation of Glycogen Synthase Kinase$3 \beta$ (GSK3 $\beta$ ) by Serotonergic Activity in Mouse Brain. Neuropsychopharmacology 2004;29:1426-1431.

75 Hui J, Zhang J, Kim H, Tong C, Ying Q, Li ZY, Mao X, Shi G, Yan J, Zhang Z, Xi G: Fluoxetine Regulates Neurogenesis In Vitro Through Modulation of GSK-3 $\beta / \beta$-Catenin Signaling. Int J Neuropsychopharmacol 2015;1-12.

76 Guseva D, Wirth A, Ponimaskin E: Cellular mechanisms of the 5-HT7 receptor-mediated signaling. Front Behav Neurosci 2014;8:1-8.

77 Meigs TE, Fields TA, McKee DD, Casey PJ: Interaction of Ga12 and Ga13 with the cytoplasmic domain of cadherin provides a mechanism for b-catenin release. PNAS 2001;98:519-524.

78 Naumenko VS, Popova NK, Lacivita E, Leopoldo M, Ponimaskin EG: Interplay between Serotonin 5-HT1A and 5-HT7 Receptors in Depressive Disorders. CNS Neurosci Ther 2014;20:582-590.

79 Anastas JN, Moon RT: WNT signalling pathways as therapeutic targets in cancer. Nature Rev Cancer 2012;13:11.

80 Sadot E, Geiger B, Oren M, Ben-Ze'ev A: Down-Regulation of $\beta$-Catenin by Activated p53. Mol Cell Biol 2001;21:6768-6781.

81 Cagatay T, Ozturk M: p53 mutation as a source of aberrant $\beta$-catenin accumulation in cancer cells. Oncogene 2002;21:7971.

82 Masuda M, Sawa M, Yamada T: Therapeutic targets in the Wnt signaling pathway: Feasibility of targeting TNIK in colorectal cancer. Pharmacol Ther 2015;156:1-9.

83 Kahn M: Can we safely target the WNT pathway? Nature reviews. Drug discovery 2014;13:513-532.

84 Lu B, Green BA, Farr JM, Lopes FCM, Van Raay TJ: Wnt Drug Discovery: Weaving Through the Screens, Patents and Clinical Trials. Cancers (Basel) 2016;8:82.

85 Hwang S-Y, Deng X, Byun S, Lee C, Lee S-J, Suh H, Zhang J, Kang Q Zhang T, Westover KD, Mandinova A, Lee SW: Direct Targeting of $\beta$-Catenin by a Small Molecule Stimulates Proteasomal Degradation and Suppresses Oncogenic Wnt/ $\beta$-Catenin Signaling. Cell Reports 2016;16:28-36.

-86 Delgado ER, Yang J, So J, Leimgruber S, Kahn M, Ishitani T, Shin D, Mustata Wilson G, Monga SP: Identification and Characterization of a Novel Small-Molecule Inhibitor of $\beta$-Catenin Signaling. Am J Pathol 2014;184:2111-2122. 